\title{
EL BILDUNSGROMAN DOMINICANO FEMENINO COMO TEXTO ANTROPOLÓGICO DE CONOCIMIENTO. JULIA ÁLVAREZ Y LA EXPERIENCIA MIGRANTE EN LOS ESTADOS UNIDOS
}

\section{DOMINICAN FEMALE BILDUNGSROMAN AS AN ANTHROPOLOGICAL TEXT OF KNOWLEDGE. JULIA ÁLVAREZ AND THE EXPERIENCE OF MIGRATION IN THE UNITED STATES}

\author{
Endika Basáñez Barrio \\ (Universidad del País Vasco UPV/EHU, España) \\ endika.basanez@ehu.eus
}

Recibido: 25 febrero 2020 Aceptado: 07 marzo 2020

Resumen: Los grandes éxodos humanos que acaecieron entre las tres islas que conforman el Caribe hispano (Cuba, Puerto Rico y República Dominicana) y los Estados Unidos a lo largo del segundo decalustro del siglo XX originaron una territorialización caribeña de presencia significativa en este último. De esta forma, comenzaron a aparecer textos ocupados en testimoniar los procesos sociológicos propios de la reciente migración y, a su vez, una tipología literaria distintiva y centrada en describir con detalle las aristas del desplazamiento exclusivamente femenino. Así surge How the García Girls lost Their Accents (1991), de la autora domínico-americana Julia Álvarez, que se ha erigido con el paso del tiempo como obra canónica del destierro dominicano femenino en los Estado Unidos. No obstante, lejos de limitarse a ocupar un lugar dentro del corpus artístico de migración femenina, la obra bien puede ser considerada como un texto antropológico de conocimiento al centrarse con exclusividad en la recepción de la mujer dominicana que, además, actúa a dos niveles: la génesis testimonial y el interés comercial. El artículo se propone, pues, analizar la obra de Álvarez como texto de divulgación antropológica siguiendo las anotaciones del profesor australiano Joel S. Khan.

Palabras clave: Literatura dominicana; literatura y mujer; literatura de género; migración y literatura; literatura antropológica. 
Abstract: The great human exoduses that took place between the three islands that make up the Hispanic Caribbean (Cuba, Puerto Rico and the Dominican Republic) and the United States throughout the second decade of the twentieth century originated a Caribbean territorialization of significant presence. This way, many texts began to testify the sociological processes of Caribbean migration and, at the same time, another literary typology of literature did start to focus on describing in detail the edges of female displacement. This is how How the García Girls lost Their Accents (1991), by Dominican-American author Julia Álvarez, has emerged as a canonical work of female Dominican displacement in the United States. However, far from being limited to occupying a place within the artistic corpus of female migration, the work may also be considered as an anthropological text of knowledge because of its intention of focusing exclusively on the integration of Dominican women in The United States, which also acts at two levels: testimonial genesis and commercial interest. The article, therefore, proposes to analyze Álvarez's work as an anthropological dissemination text following the annotations of Australian professor Joel S. Khan.

Keywords: Dominican literature; literature and woman; gender literature; migration and literature; anthropological literature.

\section{INTRODUCCIÓN}

El segundo decalustro del siglo $\mathrm{XX}$ ha sido testigo de un éxodo sin precedentes de migraciones humanas de individuos procedentes de las tres islas que componen el Caribe hispano (a saber: Cuba, República Dominicana y Puerto Rico) a los Estados Unidos y, particularmente, a la costa este del país. En efecto, son varios y diversos los motivos por los cuales los hombres y mujeres del conjunto de las tres islas hallan en el desplazamiento físico la línea de fuga (Deleuze y Parnet, 2007, 124-125) a través de la cual pueden responder a su dramático presente. Las dictaduras políticas y las crisis económicas son, fundamentalmente, los dos detonantes claramente definidos del origen de los procesos migratorios que coinciden en el eje sincrónico: el triunfo de la revolución socialista en Cuba con Fidel Castro a la cabeza (1959); el ocaso de la Operación Manos a la Obra por la que se pretendía industrializar la Isla del Encanto y la consecuente Gran Migración Puertorriqueña a los Estados Unidos (1946-1965); y el fin de la Operación Power Pack dirigida por el gobierno de Washington en la República Dominicana (1966). De esta 
forma, los índices de la población hispano-caribeña en tierra anglo-americana se vieron rápidamente elevados (Bergard y Klein, 2010, 36-41) lo que generó procesos de territorialización (Deleuze y Parnet, 2007, 124-125) típicamente caribeña en ciudades de la costa este como Nueva York en el estado homónimo, Miami en La Florida o Newark en Nueva Jersey (Luis, 2006, 526). Los procesos migratorios han dado pie, así, a la aparición de una literatura encargada de recoger en la ficción narrativa dichos procesos de desplazamiento humano a la vez que detallan las aristas del trascurso secuencial de la integración de los desplazados en la cultura estadounidense hegemónica. Dicha literatura pasa, a posteriori, a detallar también el origen de identidades híbridas entre los individuos que mantienen sus lazos culturales con sus islas de origen étnico y la realidad sociocultural de su nuevo país (Luis, 1997, X), lo que acaba por convertirla en una producción distintiva en el conjunto de literaturas hispanoamericanas escritas en los Estados Unidos. En términos sociológicos, dicha génesis se caracteriza por narrar un nuevo proceso de inculturación (Ortiz, 1983, 86-87) sin necesidad de la exculturación previa debido a las cadenas migracionales que impiden la fagocitosis de la cultura hispana subalterna, lo que redefine el análisis del padre de la noción de la transculturación, Fernando Ortiz, hasta nuestros días: "Y cada inmigrante como un desarraigo de su tierra nativa en doble trance de desajuste y de reajuste, de desculturación o exculturación y de aculturación o inculturación, y al fin, de síntesis de transculturación" (Ortiz, 1983, 87). Desplazamiento, integración, identidades híbridas y la herencia de la caribeñidad son pues materiales recurrentes en dicha producción distintiva y ciertamente característica: la literatura hispano-caribeña escrita en los Estados Unidos.

\section{EL BILDUNGSROMAN FEMENINO}

De igual modo, este corpus textual de migración y exilio comienza también a mostrarse heterogéneo desde su boom en la segunda mitad del siglo XX debido a los contextos dictatoriales y económicos que acontecen en las tres islas antillanas y empujan al desplazamiento de sus ciudadanos; no tanto en sus materiales narrativos (migración hispana en Estado Unidos) sino en su forma. Aparece así un tipo de novela escrita por mujeres desplazadas -o bien nacidas ya en tierra anglo-estadounidense, pero de ascendencia hispano-caribeña- que se encarga de testimoniar las vicisitudes propias del proceso migratorio exclusivamente femenino conformando así un espacio literario 
propio, inexistente en la literatura hispano-caribeña diaspórica hasta la fecha. Sus novelas se caracterizan por ser obras escritas por las propias mujeres, y no autores que adquieran la voz del sujeto poético femenino, que recrean en la ficción la experiencia migrante y cómo influye su condición de género en dicho desplazamiento tanto físico como mental. A esta cuestión de contenido se añade también la forma narrativa en la que las autoras emplean el eje cronológico (natural, inverso o el intercambio entre ambos) y dan detalle de su desarrollo como sujetos sociales desde su infancia hasta la adquisición de la plena madurez y su carácter subjetivo dentro de su realidad. Las obras, pues, repiten el esquema de la novela de crecimiento, más conocida en su lema alemán Bildungsroman (y, frecuentemente, también en inglés: coming-of-age) en tanto que describen el crecimiento físico del personaje principal, también mujer, en el tiempo y el desarrollo psíquico adquirido mediante las experiencias de las que son objeto. Muestra de esta génesis artística son así las obras de Nicholsa Mohr, de ascendencia boricua, y Nilda (1973); Judith Ortiz-Cofer, boricua, y su Peregrina (1986); Cristina García, cubana, y Dreaming in Cuban (1992); o Julia Álvarez, dominicana-americana, y How The García Girls lost Their Accents (1991). Precisamente, es esta última una de las obras que mejor define las particularidades del subgénero narrativo ya que respeta las particularidades formales y de contenido del Bildungsroman, pero las aplica de forma explícita a los materiales narrativos vinculados con la migración hispano-caribeña femenina en Estados Unidos. De esta forma, la autora relata la posición de subalternidad a la que se ve abocada por su condición de migrante y la precariedad y gran vulnerabilidad que esta acarrea en el medio de destino:

can believe we sisters wailed and paled, whining to go home. We didn't feel we had the best the United States had to offer. We had only second-hand stuff, rental houses in one redneck Catholic neighborhood after another, clothes at Round Robin, a black and white TV afflicted with wavy lines. Cooped up in those Little suburban houses, the rules were strict as for the Island girls, but there was no island to make up the difference (Álvarez, 1992, 107).

hasta describir con particularidad la experiencia de índole sociológica asociada a la mujer dominicana desplazada a la ciudad de Nueva York: 
I saw what a cold, lonely life awaited me in this country. I would never find someone who would understand my peculiar mix of Catholicism and agnosticism, Hispanic and American styles. [...] I did something that even as a lapsed Catholic I still did for good luck on nights before exams. I opened my drawer and took out the crucifix I kept hidden under my clothes, and I put it under my pillow for the night. This large crucifix had been a "security blanket" I took to bed with me for years after coming to this country (Álvarez, 1992, 99100).

La violencia acarreada a la experiencia migrante del cuerpo femenino desplazado a una realidad ignota hace que Yolanda, actante principal, deba crecer de forma abrupta y madurar a un ritmo que, eso sí, no coincide con exactitud con la armonía romántica del Bildungsroman arquetípico por lo que las autoras de minorías étnicas redefinen así el concepto en pro de su necesidad del relato de acuerdo al acontecimiento verídico: “[...] $\mathrm{Su}$ ser adultas toma por sorpresa al lector, lo cual apunta a una configuración de la formación que no sigue el ritmo paulatino y armonioso, como sucede en el Bildungsroman tradicional, sino abrupto y violento." (Melgar Pernías, 2012, 134). La mayor riqueza de la novela de crecimiento femenina dominicana se corresponde así con la descripción por parte de Álvarez de las experiencias que rodean la migración de la mujer a través del eje diacrónico a la vez que se sucede el crecimiento personal de la actante en su nuevo medio o, lo que es lo mismo, la mescolanza de la novela de migración femenina (en su contenido) y la novela de crecimiento redefinida ante sus necesidades (en su forma). El contenido resulta, a su vez, ciertamente genuino dado que la escritora que ha experimentado el desplazamiento desde el Caribe de habla española a los Estados Unidos, como Álvarez, se encarga de hacer un ejercicio de reordenación de vivencias biográficas para ficcionalizarlas en la construcción de su obra: "La autobiografía ofrece la oportunidad de encontrar un hilo conductor a nuestro pasado para crear eslabones en la estructura de nuestro laberinto, tan cerrado y opaco, muchas veces, para nosotras, tan ajenas a nuestros propios intereses" (Martínez Gutiérrez, 2002, 35). Atendiendo, eso sí, a un aspecto narrativo primordial: la experiencia migrante en su condición de mujer hispana o, ciertamente, la narración como testimonio biográfico: “[ ... ] la autora es la protagonista y, al mismo tiempo, la observadora de la acción que se narra y de sus circunstancias. Ese 
"yo" que analiza la sociedad de su tiempo es el sujeto íntimo que se funde con lo narrado, haciendo de lo escrito un testimonio vital a la par que un manifiesto político" (Martínez Gutiérrez, 2002, 36). Efectivamente, el desplazamiento humano como línea de fuga frente a un contexto de supervivencia no supone una misma vivencia para el hombre y para la mujer ya que, una vez más, la mujer vuelve a hallarse en un estado de mayor vulnerabilidad. Tanto las políticas institucionales como las características corpóreas de la fémina juegan en su contra para su integración completa en la obra de Álvarez. El cuerpo de la mujer genera así una tensión debido al falocentrismo socio-político que vulnera su poder de elección subjetivo y la empuja a la resignación:

"You know," he said, "I thought you'd be hot-blooded, being Spanish and all, and that under all the Catholic bullshit, you'd be really free [...] But Jesus, you're worse than a fucking Puritan." I felt stung to the quick. I got up and threw my coat over my nightgown, packed up my clothes, and left the room (Álvarez, 1992, 99).

El Bildungsroman de migración femenino dominicano se erige, por tanto, como un texto que bebe de forma intrínseca de las experiencias de las mujeres que han abordado el trauma del destierro forzoso y rezuma la autenticidad del desgarro de la desterritorialización tanto en términos físicos como emocionales. Julia Álvarez (al igual que Cristina García o Nicholasa Mohr) han sido cuerpos migrantes y su literatura se corresponde con el dolor característico del recuerdo de dicha experiencia. En efecto, no solo las mujeres hispano-caribeñas migradas a Estados Unidos han empleado el Bildungsroman como forma de ficción del recuerdo sino que otras mujeres de ascendencia latina como Gloria Alzaldúa, Cherri Moraga o Sandra Cisneros, todas ellas chicanas, también han escrito sus novelas de crecimiento a medio camino entre la experiencia migrante y la forma del coming-of-age originando así una trayectoria de mayor envergadura y heterogeneidad de mujeres pertenecientes a la minoría étnica hispana en los Estados Unidos. 


\section{TEXTOS ANTROPOLÓGICOS DE CONOCIMIENTO}

Dado que los textos de crecimiento escritos por mujeres hispano-caribeñas dan detalle de las vivencias de su desplazamiento, su integración en el nuevo medio cultural y los conflictos generados de estos dos procesos (como la pérdida y la posterior búsqueda de su identidad) podemos afirmar que, sin duda alguna, ofrecen al lector la adquisición del conocimiento de la experiencia migrante femenina relatada, efectivamente, por las propias autoras desplazadas. De ahí a la relevancia de dichas obras que espiran la autenticidad de la vivencia verídica y se convierten en testimonio "semiautobiográfico" (Trupe, 2001, 21) a través del recuerdo de la autora. Así, pues, el lector de la novela adquiere una información específica y detallada del destierro de las mujeres caribeñas en tierra anglo-estadounidense a través de la intrahistoria narrada en las mismas y, desde esta posición de intimidad individualizada, acceden a acontecimientos de índole histórica como los éxodos humanos entre el Caribe español y los Estados Unidos en la segunda mitad del siglo XX. Es decir, el lector accede desde la experiencia particular a un conocimiento colectivo por lo que actúa como un texto antropológico sustentado, a su vez, en las biografías de las escritoras. En efecto, el profesor de sociología y antropología en la Universidad de La Trobe en Victoria (Australia) alude en su Culture, Multiculture y Postculture (1995) al valor antropológico que adquieren las obras artísticas ya que, a pesar de que estas sean realizadas por escritoras y no antropólogas, ofrecen en sus obras testimoniales las peculiaridades de sus experiencias y, de manera más precisa, representaciones. Es decir, las obras recogen en la ficción la existencia de nueva información antropológica para un público desconocedor de la misma que a posteriori las consume como producto de ocio y adquiere así dicha información, de forma que los textos antropológicos artísticos no solo recogen un contenido histórico de un determinado pueblo o cultura, sino que, además, expanden dicho testimonio al resto del mundo:

In the language of cultural theory, the "Mexican Indians" of B. Traven`s novel, [...] the "Negroes" who populare DuBose Heyward's Porgy [...] are all representation. They are, moreover, representations of a particular kind: of what al least now we have come to call other cultures [...] In other words. Treasure, Porgy $[\ldots]$ are all anthropological text in the broad sense of that term. While neither Traven [nor] Heyward [...] was a professional anthropologist, they all 
nonetheless were performing the intellectual function which their contemporaries -like Bronislaw, Malinowski Franz Boas [...]- were claiming for themselves (Khan, 1995, 2).

El contenido del relato se transforma así, al igual que apunta Khan, en representaciones de la experiencia migrante femenina que se difunden mediante la literatura a pesar de que esta pertenezca al campo artístico y no a la ciencia antropológica stricto sensu. La literatura, de igual modo, es capaz de llegar a un público de mayor número como producto de consumo dispuesto a ser recibido por el lector sin necesidad de que sea docto en la materia, a diferencia de la disciplina académica, por lo que recrea formas de representación que las sociedades conforman acerca de lugares, culturas y gentes que le son ajenas (como la realidad dominicana narrada por Álvarez para, por ejemplo, la colectividad occidental). La divulgación de las obras, que además se adecúan al idioma del pueblo receptor, ofrece un valor claramente didáctico sobre las migraciones femeninas desde el detalle individual (dominicano, en este caso) hasta el colectivo (caribeño e hispanoamericano) y, en suma, conocimientos antropológicos a pesar de tratase de creadoras de contenido artístico. En este sentido, cabe hacer alusión a que los textos obedecen así al precepto grecolatino docere et delectare porque detallan su experiencia migrante a través de un testimonio didáctico mientras establecen una conexión entre sus recuerdos y la génesis de una obra artística con la finalidad comercial que requiere apelar al interés del lector. La literatura de Álvarez se convierte así en emblema de las vivencias migrantes de las mujeres dominicanas en los Estados Unidos para el público de su obra quien recrea las representaciones en su imaginario colectivo y conforma, en última instancia, el producto de ocio que supone el texto en conocimiento.

\section{CONCLUSIONES}

Si bien el lema literatura hispano-caribeña escrita en Estados Unidos responde a la presencia de autores de ascendencia homónima en Norteamérica, cierto es que su vasta génesis textual se vincula, a su vez, con un nutrido corpus de obras que atienden a las experiencias de los migrantes. Aparece, así, un tipo de producción literaria distintiva llevada a cabo de forma exclusiva por mujeres migrantes caribeñas sobre mujeres migrantes caribeñas desde la cual surgen textos que presentan semejanza a los preceptos 
del Bildungsroman aunque, como hemos analizado, redefinen el esquema a sus necesidades en pro de la narración de las experiencias de vulnerabilidad y, en última instancia, subalternidad (doble por su condición genérica de migrantes y concreta de mujeres hispanas). La misma, en sí, supone pues una reformulación de los géneros contemporáneos ante la necesidad de un discurso que ha de adaptar el contenido al continente y, a través de ello, emplear la narración como testimonio pseudo-biográfico (en tanto que literario aunque siempre asociado a sus propias vivencias) en el que la armonía del Bildungsroman se ve interrumpida por el desarraigo y la precariedad de su situación. De forma nada anecdótica, How the García Girls lost Their Accents se ve afectada por un doble propósito: testimoniar y divulgar; y obedecer a intereses comerciales. En este mismo sentido, el texto de Álvarez ofrece así una información de índole antropológica que parte de la experiencia hispano-caribeña individual, dominicana en este caso, hacia la colectividad del grueso de las migrantes de ascendencia pancaribeña en tierra anglo-estadounidense y, a través de ello, da detalle de los acontecimientos políticos que actúan como contextos de su proceso de desplazamiento. La obra cumple así con el precepto del docere et delectare que le permite ser herramienta de divulgación (contenido) y producto de consumo (continente). La novela de desplazamiento femenino, a su vez, no deja de inaugurar y ocupar un lugar típicamente hecho por y para los escritores masculinos como es la novela de migración y exilio, que se asemeja a la femenina en su condición de migrantes subalternos, pero difiere en las aristas que aluden explícitamente a aquellas que envuelven el tránsito e integración del cuerpo de mujer en el medio. En suma, el coming-of-age caribeño femenino viene así a ejecutarse como un texto antropológico de conocimiento de la realidad de las mujeres latinoamericanas migrantes desde la perspectiva del desgarro, el dolor y las vulnerabilidades que en su situación de doble discriminación (migrante y mujer) ayudan a divulgar la experiencia del ser humano (mujer) en su abandono físico forzoso de la realidad conocida como supervivencia de un contexto político-económico que la empuja a la subalternidad dentro de su nuevo medio receptor. 


\section{RECURSOS BIBLIOGRÁFICOS}

Álvarez, Julia. (1992[1991]). How The García Girls lost Their Accents. Nueva York: Plume Printing.

Bergad, Laid y Herbert S. Klein (2010). Hispanics in the United States. A Demographic, Social, and Economic History, 1980-2005, Estados Unidos, Cambridge University Press.

Dedeluze, Gilles y Claire Parnet (2007 [1977]). Dialogues II. Nueva York: Columbia University Press.

García, Cristina (1992). Dreaming in Cuban. New York: Ballantine Books.

Khan, Joel (1995). Culture, Multiculture and Postculture. Londres: SAGE Publications

Luis, William (1997). Dance Between Two Cultures: Latino Caribbean Literature Written in the United States. Nashville: Vanderbilt University Press.

- (2006). "Literatura latinoamericana (hispano-caribeña) escrita en los Estados Unidos”. Historia de la literatura hispanoamericana II. El siglo XX. Madrid: Gredos.

Martínez Gutiérrez, Josebe (2002). Las intelectuales de la Segunda República al exilio. Madrid: Daneyu.

Melgar Pernías, Yolanda (2012) Los Bildungsromane femeninos de Carmen Boullosa y Sandra Cisneros. Mexicanidades, fronteras, puentes. Wodbridge: Tamesis.

Mohr, Nicholasa (1973). Nilda. Huston: Arte Público Press

Ortiz Cofer, Judith (1986). Peregrina. Golden: Riverstone Press of the Foothills Arts Center.

Ortiz, Fernando (1983 [1940]). Del fenómeno social de la "transculturación" y de su importancia en Cuba. Contrapunteo cubano del tabaco y del azúcar. La Habana: Editorial de Ciencias Sociales.

Trupe, Alice (2011). Reading Julia Álvarez. Santa Bárbara: ABC-CLIO. 